\title{
Energy performance of a ventilation system for an apartment according to the Italian regulation
}

\author{
P. Valdiserri $\cdot$ C. Biserni $\cdot$ M. Garai
}

Received: 15 July 2014/ Accepted: 27 December 2014/Published online: 24 January 2015

(C) The Author(s) 2015. This article is published with open access at Springerlink.com

\begin{abstract}
According to recent regulations on energy saving in buildings, all new structures should guarantee high-energy performance. To this aim, the building envelope should be equipped with insulated walls and high-efficiency windows. This approach leads to considerable thermal insulation, but at the same time, in the absence of a suitable ventilation system, it results in a worsening of indoor air quality. A healthy quality of life requires good indoor air quality; especially in places where people spend most of their time, adequate air exchanges should be guaranteed and indoor pollution reduced to "acceptable" levels. In the present work, we performed a dynamic simulation of a ventilation system for an apartment using a mathematical model, i.e., the Trnsys commercial code. The model has been applied to an apartment of $66 \mathrm{~m}^{2}$ inside a condominium located in Bologna (Italy), but can also be used for other types of buildings as well. The variation of energy request due to different measurements of volume flow rate was evaluated.
\end{abstract}

Keywords Heat recovery - Thermal envelope ·

Ventilation

\section{Introduction}

European residential and tertiary buildings are responsible for $40 \%$ of final energy consumption. Energy consumption

Published in the Special Issue "8th AIGE Conference (Italian Association for Energy Management)".

P. Valdiserri · C. Biserni $(\bowtie) \cdot$ M. Garai

Department of Industrial Engineering (DIN), School of

Engineering and Architecture, Alma Mater Studiorum,

University of Bologna, Viale Risorgimento 2,

40136 Bologna, Italy

e-mail: cesare.biserni@unibo.it for domestic use in Europe is estimated around $35 \%$ of the total primary energy used $[1,2]$. Therefore, the building sector has a very high potential in terms of reducing consumption and lowering emissions. To reduce this consumption, the European Community issued Directive 2002/91 on Building Energy Certification, [3] which came into effect in Italy through the Legislative Decree no. 192/2005 [4] and no. 311/2006 [5]. Unfortunately, it should be noted that on the Italian territory $\left(301,336 \mathrm{~km}^{2}\right)$, existing dwellings have a very high density (about 27 million units). Also, statistic studies confirmed that between 1971 and 2001, these were augmented approximately by $36 \%$, because of the growth in population by $55 \%$ and the number of families by $26 \%$ [1]. Therefore, even though a certain percentage of the new buildings are energetically more efficient, the energy consumption is still globally increasing. The above-mentioned need to reduce energy consumption in new buildings implied the use of considerable thermal insulation, but at the same time in the absence of a suitable ventilation system it could result in a worsening of indoor air quality. A healthy quality of life requires good indoor air quality; especially in places where people spend most of their time, adequate air exchanges should be guaranteed to reduce indoor pollution to "acceptable" levels.

Due to the increasing indoor air quality standard, the ventilation loads constitute a growing part of the heating demand between 20 and $50 \%$ for new and retrofitted buildings [6,7], depending on building insulation, compactness, air change rate, indoor heat sources, indoor set points and outdoor climate. Heat recovery ventilation (HRV) principle is to recover heat from the exhaust air and to transfer it to the supply air through a heat exchanger. With the growing share of ventilation heating loads, heat recovery over the mechanical ventilation systems appears 
as one of the key solutions to reduce heat losses and generate consequent energy savings [8]. With rapid economic growth, the need for better indoor built environment has become more pronounced. Both thermal comfort and indoor air quality issues have gained increasing attention. Adequate ventilation is necessary to maintain a desired indoor air quality [9-11].

In the present work, we performed a dynamic simulation of a ventilation system for an apartment using a mathematical model, i.e., the Trnsys commercial code [12]. Trnsys is an extensible simulation environment for the transient simulation of energy systems including multizone buildings. It is used to validate new energy concepts, design and simulation of buildings and their equipment, including control strategies, occupant behavior and alternative energy systems (wind, solar, photovoltaic, hydrogen systems, etc.).

The variation of the energy request due to different measurements of volume flow rate has been contemplated in this study, according to the Italian regulation on residential buildings.

\section{Description of the cases under investigation}

The numerical model has been applied to an apartment of $66 \mathrm{~m}^{2}$ inside a condominium located in Bologna (Italy), but can also be used for other types of buildings, as well. The apartment, highlighted in Fig. 1, is a six-roomed flat.
Table 1 Surface of each room of the apartment and acronyms adopted in the simulations

\begin{tabular}{lll}
\hline Room & Surface $\left(\mathrm{m}^{2}\right)$ & Acronym \\
\hline Kitchen & 10.07 & $\mathrm{~K}$ \\
Living room & 18.87 & $\mathrm{LR}$ \\
Bedroom 1 & 12.54 & $\mathrm{~B} 1$ \\
Bedroom 2 & 13.07 & $\mathrm{~B} 2$ \\
Access corridor & 5.13 & AC \\
Bathroom & 6.18 & $\mathrm{~B}$ \\
\hline
\end{tabular}

Table 1 illustrates the surface of each room and the acronyms used in the calculations.

Table 2 highlights the thermal characteristics of the apartment envelope.

To simulate the ventilation system working, four people are supposed to live in the apartment, according to the timetable shown in Table 3.:

It is worth noting from Table 3 that between 7 a.m. to midday nobody is at home. We performed a dynamic simulation of a ventilation system for the above-described apartment by means of the Trnsys commercial code. We studied the performance of the ventilation system in four different conditions. All the cases under investigation are referred to the period when the heating system is switched on (winter period), for Bologna from October 15 to April 15. The heating system is supposed to operate $14 \mathrm{~h}$ a day according to the following timetable:

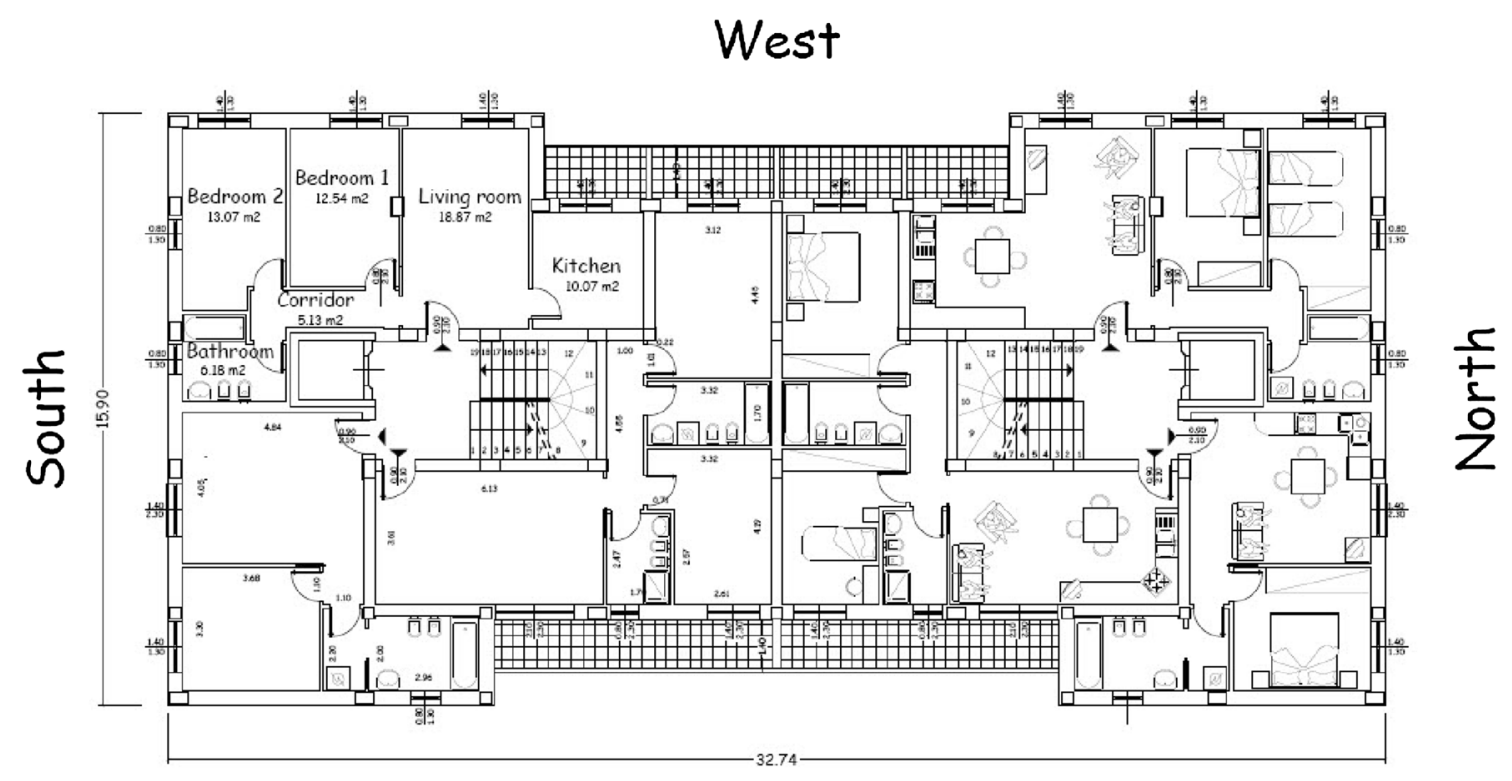

East

Fig. 1 Plan of the studied apartment 
- from 5 a.m. to 10 a.m;

- from 12 p.m. to 2 p.m;

- from 4 p.m. to 11 p.m.

The heating system is set to maintain the internal temperature of $20^{\circ} \mathrm{C}$ in all rooms.

\section{Case 1}

It is characterized by an air change rate (ventilation and infiltration) of $0.3 \mathrm{~h}^{-1}$ for all the rooms, except the kitchen and the bathroom which have 0.9 air changes per hour.

\section{Case 2}

It is characterized by the presence of a heat recovery ventilation system that can save energy from the ejected air, as depicted in Fig. 2. The ventilation system is equipped with two fans that absorb individually the power of $30 \mathrm{~W}$. The model employs a cross flow heat exchanger able to exchange heat, but unable to exchange humidity since the two air fluxes are kept separate by specific sealing in the plates. Any air infiltration, contaminant gases (polluting materials), biological hazards and particulates are completely blocked.

Table 2 Values of thermal transmittance with regard to the envelope elements

\begin{tabular}{ll}
\hline Envelope element & Thermal transmittance $\mathrm{U}\left(\mathrm{W} \mathrm{m}^{-2} \mathrm{~K}^{-1}\right)$ \\
\hline Outside walls & 0.47 \\
Inside walls & 0.64 \\
Floor and ceiling & 0.39 \\
Windows & 2.83 \\
\hline
\end{tabular}

Table 3 Timetable of people present in each room of the apartment

\begin{tabular}{lll}
\hline Timetable & Room & Number of people \\
\hline 11 p.m.-7 a.m. & B1 & 2 \\
11 p.m.-7 a.m. & B2 & 2 \\
midday-2 p.m. & K & 2 \\
2 p.m.-7 p.m. & LR & 2 \\
7 p.m.-9 p.m. & K & 4 \\
9 p.m.-11 p.m. & LR & 4 \\
\hline
\end{tabular}

The efficiency of the heat recovery system is defined as follows:

$\varepsilon=\frac{T_{S}-T_{0}}{T_{R}-T_{0}}$,

where $T_{S}$ is the temperature of the supply air; $T_{O}$ is the temperature of the external air (outdoor air); $T_{R}$ represents the temperature of the extracted air (return air); the heat recovery efficiency values adopted in the simulations are $\varepsilon=0.6$ and 0.8 .

The above-mentioned ventilation system extracts air from the bathroom and the kitchen, with the mass flow rate vales of, respectively, 28.3 and $46.0 \mathrm{~kg} \mathrm{~h}^{-1}$. The fresh air enters the living room and the two bedrooms with the following mass flow rate:

- $31.5 \mathrm{~kg} \mathrm{~h}^{-1}$ of external air in the living room;

- $21.0 \mathrm{~kg} \mathrm{~h}^{-1}$ of external air in bedroom 1 ;

- $21.8 \mathrm{~kg} \mathrm{~h}^{-1}$ of external air in bedroom 2 .

Finally, it is important to highlight that 0.1 air changes per hour for infiltration are considered and it is worth underlining that the total amount of ventilation and infiltration in Case 2 corresponds to the same quantity used in Case 1.

\section{Case 3}

In this case, the ventilation system operates, without heat recovery, for a total period of $6 \mathrm{~h}$, precisely:

- from 7 a.m. to 9 a.m;

- from 12 p.m. to 2 p.m;

- from 7 p.m. to 9 p.m.

The above-mentioned ventilation system extracts air from the bathroom and the kitchen, with the mass flow rate values of, respectively, 113.0 and $184.2 \mathrm{~kg} \mathrm{~h}^{-1}$. The fresh air coming from outside enters the living room and the two bedrooms with the following mass flow rate:

- $126.1 \mathrm{~kg} \mathrm{~h}^{-1}$ of external air in the living room;

- $83.8 \mathrm{~kg} \mathrm{~h}^{-1}$ of external air in bedroom 1;

- $87.3 \mathrm{~kg} \mathrm{~h}^{-1}$ of external air in bedroom 2 .

The infiltration of 0.1 air changes per hour remains unvaried.

Fig. 2 Heat recovery system

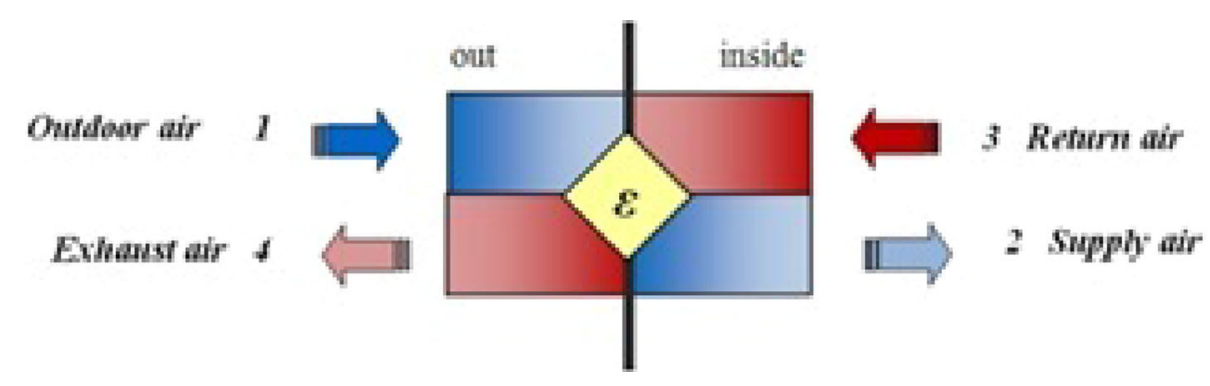


Table 4 Monthly and total energy demand with reference to Case 1

\begin{tabular}{lc}
\hline Month & Total energy demand, Q [kWh] \\
\hline October (15 days) & 104 \\
November & 785 \\
December & 1,347 \\
January & 1,406 \\
February & 1,086 \\
March & 513 \\
April (15 days) & 72 \\
Total & 5,312 \\
\hline
\end{tabular}

Case 4

It is similar to Case 3, but in the presence of the heat recovery system. The ventilation system is equipped with two fans that absorb individually the power of $60 \mathrm{~W}$. The external air enters the heat recovery and reaches the living room, bedroom 1 and bedroom 2 with the same ventilation rates of Case 3 and $6 \mathrm{~h}$ per day of total operation. The exhaust air is extracted from the bathroom and the kitchen and expelled outside after having preheated the inlet air. The heat recovery efficiency values adopted in the simulations are still $\varepsilon=0.6$ and 0.8 .

\section{Results and discussion}

\section{Case 1}

The energy need for building heating in the considered interval (from 15 October to 15 April) is highlighted in Table 4.:

The yearly energy demand for the envelope of 5,312 $\mathrm{kWh}$ referred to the unit surface becomes $80.7 \mathrm{kWhm}^{-2}$ per year. The part due to ventilation and infiltration is 0.3 air changes per hour for all the rooms, except the kitchen and the bathroom which have 0.9 , results equal to 1,470 $\mathrm{kWh}$ per year and per unit surface $22.3 \mathrm{kWhm}^{-2}$ per year.

\section{Case 2}

Consider the heat recovery working $24 \mathrm{~h}$ per day; during the winter period (183 days), the energy demand referred to building heating is highlighted in Table 5 .

From Table 5, the yearly energy demand for the envelope, when $\varepsilon=0.6$, is equal to $4,583 \mathrm{kWh}$ and when referred to the unit surface becomes $69.6 \mathrm{kWhm}^{-2}$ per year. Similarly, the energy demand, when $\varepsilon=0.8$, is equal to $4,353 \mathrm{kWh}$ and when referred to the unit surface becomes $66.1 \mathrm{kWhm}^{-2}$ per year.
Table 5 Monthly and total energy demand with reference to Case 2

\begin{tabular}{lcc}
\hline Month & \multicolumn{2}{c}{ Total energy demand, Q [kWh] } \\
\cline { 2 - 3 } & $\varepsilon=0.6$ & $\varepsilon=0.8$ \\
\hline October (15 days) & 68 & 57 \\
November & 675 & 641 \\
December & 1,190 & 1,141 \\
January & 1,228 & 1,171 \\
February & 950 & 907 \\
March & 414 & 383 \\
April (15 days) & 58 & 53 \\
Total & 4,583 & 4,353 \\
\hline
\end{tabular}

Table 6 Monthly and total energy demand with reference to Case 3

\begin{tabular}{lc}
\hline Month & Total energy demand, Q (kWh) \\
\hline October (15 days) & 120 \\
November & 809 \\
December & 1,380 \\
January & 1,447 \\
February & 1,116 \\
March & 539 \\
April (15 days) & 75 \\
Total & 5,486 \\
\hline
\end{tabular}

Case 3

The energy demand referred to building heating in the winter period is highlighted in Table 6.

The yearly energy demand for the envelope of 5,486 $\mathrm{kWh}$ referred to the unit surface becomes $83.3 \mathrm{kWhm}^{-2}$ per year. The part due to ventilation results in augmentation if compared to that of Case 1 because during the $6 \mathrm{~h}$ of functioning the heat generator is permanently switched on in order to maintain the fixed temperature of $20{ }^{\circ} \mathrm{C}$ in all the apartment.

Case 4

Consider the heat recovery working $6 \mathrm{~h}$ per day; during the winter period (183 days), the energy need for building heating is highlighted in Table 7.

From Table 7 , the yearly energy demand for the envelope, when $\varepsilon=0.6$, is equal to $4,683 \mathrm{kWh}$ and when referred to the unit surface becomes $71.1 \mathrm{kWhm}^{-2}$ per year. Similarly, total yearly energy demand, when $\varepsilon=0.8$, is equal to $4,412 \mathrm{kWh}$ and when referred to the unit surface becomes $67.0 \mathrm{kWhm}^{-2}$ per year. 
Table 7 Monthly and total energy demand with reference to Case 4

\begin{tabular}{lcc}
\hline Month & \multicolumn{2}{c}{ Total energy demand, Q (kWh) } \\
\cline { 2 - 3 } & $\varepsilon=0.6$ & $\varepsilon=0.8$ \\
\hline October (15 days) & 74 & 60 \\
November & 690 & 649 \\
December & 1,211 & 1,154 \\
January & 1,253 & 1,187 \\
February & 968 & 918 \\
March & 427 & 390 \\
April (15 days) & 60 & 54 \\
Total & 4,683 & 4,412 \\
\hline
\end{tabular}

Table 8 Energy need for building heating in terms of primary energy with reference to all the investigated cases

\begin{tabular}{llll}
\hline & $\begin{array}{l}\text { Yearly energy } \\
\text { demand for } \\
\text { heating }(\mathrm{kWh})\end{array}$ & $\begin{array}{l}\text { Yearly energy } \\
\text { demand for heat } \\
\text { recovery }(\mathrm{kWh})\end{array}$ & $\begin{array}{l}\text { Total yearly energy } \\
\text { demand per unit } \\
\text { surface }\left(\mathrm{kWhm}^{-2}\right)\end{array}$ \\
\hline Case 1 & 6,249 & - & 94.7 \\
Case 2A & 5,392 & 573 & 90.4 \\
Case 2B & 5,121 & 573 & 86.3 \\
Case 3 & 6,454 & - & 97.8 \\
Case 4A & 5,509 & 286 & 87.8 \\
Case 4B & 5,191 & 286 & 83.0 \\
\hline
\end{tabular}

Comparative analysis

Considering a global heating system efficiency equal to 0.85 , the yearly energy demand can be highlighted in terms of primary energy, as shown in Table 8.

With reference to Case 2, the consumption of primary energy of the heat recovery system (two fans that absorb individually the power of $30 \mathrm{~W}$ ), considering 183 days (24 h per day) and a conversion factor of 0.46 , is $573 \mathrm{kWh}$; when referred to the unit surface it becomes $8.7 \mathrm{kWhm}^{-2}$ per year. According to the considered hypothesis on the heat recovery working period, when the efficiency is 0.8 (Case 2B), it is possible to save, in comparison with Case 1, $555 \mathrm{kWh}$ per year (that per unit area corresponds to 8.4 $\mathrm{kWhm}^{-2}$ ) and only $285 \mathrm{kWh}$ per year (that per unit area corresponds to $4.3 \mathrm{kWhm}^{-2}$ ) when the efficiency is 0.6 (Case 2A).

Similarly, with reference to Case 4 , the consumption of primary energy of the heat recovery system (two fans that absorb individually the power of $60 \mathrm{~W}$ ), considering 183 days ( $6 \mathrm{~h}$ per day) and a conversion factor of 0.46 , is $286 \mathrm{kWh}$; when referred to the unit surface it becomes 8.7 $\mathrm{kWhm}^{-2}$ per year. According to the considered hypothesis on the heat recovery working period, when the efficiency is
0.8 (Case 4B), it is possible to save, in comparison with Case 3, $978 \mathrm{kWh}$ per year (that per unit area corresponds to $14.8 \mathrm{kWhm}^{-2}$ ) and $659 \mathrm{kWh}$ per year (that per unit area corresponds to $10.0 \mathrm{kWhm}^{-2}$ ) when the efficiency is 0.6 (Case 4A).

Analysis of temperature diagrams

Figure 3 highlights the temporal trend of temperatures referring to a typical winter day, i.e., January 15 . The diagram is directly referred to the simulations performed in Case 2 , but can be extended also to Case 4 , provided that the temporal interval is limited to $6 \mathrm{~h}$. On the ordinate axis, the external temperature scale (right) and the supply air temperature (left) are shown in case the heat recovery efficiency is $\varepsilon=0.6$ (bottom) and 0.8 (top). It is worth noting that in the supply air temperature trend, the maximum temperatures of almost 16 and $12{ }^{\circ} \mathrm{C}$, respectively, when $\varepsilon=0.8$ and 0.6 , are due to the working of the heating system. Figure 4 highlights the air temperature temporal trend with reference to Bedroom 2 in a typical winter night (between January 15 and 16). All the investigated cases have been contemplated: case $2 \mathrm{~A}$ and $4 \mathrm{~A}$ correspond to $\varepsilon=0.6$ and, similarly, case $2 \mathrm{~B}$ and $4 \mathrm{~B}$ correspond to $\varepsilon=0.8$.

Two persons sleeping in Bedroom 2 is expected according to the initial hypothesis. Moreover, it is interesting to observe that Bedroom 2 is located at the corner of the apartment, so that the building envelope is particularly exposed to heat losses. Based on pure observation, the temporal trend referred to Case 3 and 4 is affected by the occurrence of infiltration with no air ventilation.

\section{Conclusions}

In the present work, we performed a dynamic simulation of a ventilation system for an apartment using a mathematical model, i.e., the Trnsys commercial code, in the context of the Italian regulation [13].

The model has been applied, with reference to the winter period, to an apartment of $66 \mathrm{~m}^{2}$ inside a condominium located in Bologna (Italy), but can also be used for other types of buildings as well. The ventilation system treated here used both external air supply (Cases 1-3) and fresh air which came across a heat recovery unit (Cases 2-4), having constant flow rate.

Several conclusions and ideas for future research emerged from this study:

- When the system works $24 \mathrm{~h}$, an evident energy consumption for ventilators occurs. 
Fig. 3 Temporal trend of the external temperature and of the supply air temperature with reference to Case 2

Fig. 4 Temporal trend of air temperature during a typical winter night in Bedroom 2 with reference to all the investigated cases

- If the total amount of fans' energy absorption exceeds the power of $60 \mathrm{~W}$, the use of the heat recovery exchanger could be no more advisable. With reference to the case treated here, a weak energy gain occurs and it is more pronounced when the HR efficiency is equal to 0.6 .

- If the ventilation system works during a limited time interval (Case 4), with the heating system switched on, an incremented air mass flow rate has to be managed so that fans absorb more power. However, the present case has highlighted a considerable energy gain, with the hypothesis of total power of the HR equal to $120 \mathrm{~W}$.

In future works, these conclusions based on energy performance comparisons should be balanced by at least two other criteria: indoor air quality and investment costs.

Acknowledgments The authors wish to thank the Italian Ministry of Education, University and Research for funding this study. 
Open Access This article is distributed under the terms of the Creative Commons Attribution License which permits any use, distribution, and reproduction in any medium, provided the original author(s) and the source are credited.

\section{References}

1. Aste, N., Adhikari, R.S., Compostella, J., Del Pero, C.: Energy and environmental impact of domestic heating in Italy: evaluation of national NOx emissions. Energy Policy 53, 353-360 (2013)

2. Directive 2010/31/EU of the European Parliament and of the Council of 19 May 2010 on the energy performance of buildings (recast) (2010)

3. Directive 2002/91/CE of the European Parliament, 16 Dec 2002 (2002)

4. Legislative Decree n 192, 19 Aug 2005 (2005)

5. Legislative Decree n 311, 29 Dec 2006 (2006)

6. Simonson, C.: Energy consumption and ventilation performance of naturally ventilated ecological house in a cold climate. Energy Build. 37, 23-35 (2005)
7. Orme, M.: Estimates of the energy impact of ventilation and financial expenditures. Energy Build. 33, 199-205 (2001)

8. El Fouih, Y., Stabat, P., Rivière, P., Hoang, P., Archambault, V.: Adequacy of air-to-air heat recovery ventilation system applied in low energy buildings. Energy Build. 54, 29-39 (2012)

9. Calautit, J.K., Hughes, B.R., Chaudhry, H.N., Ghani, S.A.: CFD analysis of a heat transfer device integrated wind tower system for hot and dry climate. Appl. Energy 112, 576-591 (2013)

10. Hughes, B.R., Chaudhry, H.N., Calautit, J.K.: Passive energy recovery from natural ventilation air streams. Appl. Energy 113, $127-140$ (2014)

11. Liu, X.P., Niu, J.L.: An optimal design analysis method for heat recovery devices in building applications. Appl. Energy 129, 364-372 (2014)

12. Solar Energy Laboratory, Manual of TRNSYS 16-a TRaNsient SYstem Simulation program (2006)

13. UNI TS 11300-1, Determination of the buildings energy demand for the air-conditioning in summer and winter 